Check for updates

Cite this: RSC Adv., 2019, 9, 1247

Received 31st October 2018 Accepted 19th December 2018

DOI: 10.1039/c8ra09036j

rsc.li/rsc-advances

\section{Effect of small molecular weight soybean protein- derived peptide supplementation on attenuating burn injury-induced inflammation and accelerating wound healing in a rat model}

\author{
Fen Zhao, (DD $\dagger^{a}$ Wei Liu, $\dagger^{b}$ Yonghui Yu, ${ }^{* a}$ Xinqi Liu, ${ }^{* a}$ Huinan Yin, ${ }^{b}$ Lingying Liu ${ }^{b}$ \\ and Guofu $\mathrm{Yi}^{\mathrm{a}}$
}

The populations most afflicted by burn injuries have limited abilities to support the significant specialized requirements and costs for acute and long-term burn injury care. This article describes the results of optimizing the use of readily absorbed small molecular weight soybean protein enzymolysis-derived peptide to attenuate rat burn injury-induced inflammation and accelerate wound healing. A major fullthickness 30\% total body surface area burn-injury rat model was utilized and the systemic white blood cell (WBC) counts, the relative level of stimulation index of respiratory burst, and the inflammatory markers procalcitonin (PCT), tumor necrosis factor $-\alpha$ (TNF- $\alpha$ ), chemokine (C-C motif) ligand $3(C C L-3)$, chemokine ( $\mathrm{C}-\mathrm{C}$ motif) ligand 11 (CCL-11) and interleukin-10 (IL-10) were assessed. The burn injuryinduced neutrophil and macrophage immune cell infiltration of the cutaneous tissues was detected by immunohistochemical analysis of the protein markers myeloperoxidase (MPO) and cluster of differentiation 68 (CD-68). The local induction of the burn injury-induced toll-like receptor 4/nuclear factor kappa-light-chain-enhancer of activated $B(T L R 4 / N F-\kappa B)$ signaling pathway in the effected cutaneous tissues was determined by the quantification of the protein expression of TLR4 and phosphorylated NF- $\mathrm{BB} / \mathrm{p} 65$ using Western blots. In addition, burn wound size and healing rate were assessed biweekly for 8 weeks by imaging and measuring the burn wound surface area, and the angiogenesis protein marker of cluster of differentiation 31 (CD-31) expression in cutaneous tissues was also detected by immunohistochemical analysis. The results showed that nutrient supplementation with optimized readily absorbed small molecular weight soybean protein-derived peptide resulted in a dramatic anti-inflammatory effect as evidenced by the significant increase in the burn injury-induced systemic white blood cell counts and their relative level of stimulation index of respiratory burst, reduction in the burn injury-induced activation of NF- $\kappa \mathrm{B}$ transcriptional signaling pathways, significant reduction in the local burn injury-induced cutaneous infiltration of neutrophils and macrophages at all measured time points, reduction in wound size and improved rate of burn injury wound healing with increased CD-31 protein expression. These results indicated that dietary supplementation with small molecular weight soybean-derived peptides could be used as an adjunct therapy in burn injury management to reduce inflammation and improve overall patient outcomes.

\section{Introduction}

Burn injuries are estimated to result in 265000 deaths annually, ${ }^{1}$ and the global reported frequency of thermal burn injuries is 67 million. ${ }^{2}$ Severe nonfatal burn injuries are a prevalent and

\footnotetext{
${ }^{a}$ Beijing Advanced Innovation Center for Food Nutrition and Human Health, Beijing Engineering and Technology Research Center of Food Additives, Beijing Technology and Business University, Beijing 100048, China. E-mail: yonghuiwh@126.com; liuxinqi@btbu.edu.cn

${ }^{b}$ Burn Institute, The First Affiliated Hospital of PLA General Hospital, Beijing 100048, China

$\dagger$ Fen Zhao and Wei Liu contributed equally to this work.
}

burdensome global health problem because they result in prolonged hospitalization, commonly result in secondary infections $^{3}$ and usually require multiple surgical treatments, specialized care and equipment, rehabilitation procedures and often result in disfigurement and lifelong disability. ${ }^{4}$ Burn care represents one of the most expensive conditions in health care to treat. ${ }^{5}$

Severe full-thickness, third-degree burn injuries (major burn injuries) result from cell and tissue damage and death caused by exposure to extreme heat or cold, friction, caustic chemicals, electricity or radiation. ${ }^{3}$ Initially, these injuries present in humans as painless, stiff, leathery white to brown skin areas. ${ }^{4}$ 
Autophagy and apoptosis of the damaged cells occurs at the site of injury within the first day and delayed phase apoptosis occurs the day after the burn injury, and cellular necrosis causes the progression from a burn injury to a burn wound. ${ }^{6,7}$ Major burns rapidly induce a significant local inflammatory response and an acute systemic response, ${ }^{3}$ playing a central role in the complex dynamics of burn wound healing. Inflammation is induced to degrade necrotic tissue, prepare to protect the compromised area from pathogenic invasion and activate wound repair signaling proteins. ${ }^{8}$ Inflammatory reactions are often accompanied by fever and leukocytosis. The initial inflammatory response recruits neutrophils and monocytes to the site of injury, which recruit additional inflammatory proteins. This effect is further sustained by macrophage chemokines, followed by the migration of keratinocytes to the site of the injury and fibroblast activation, assisting in the revascularization of the damaged tissue and wound closure. The new wound tissue then matures through the deposition of collagen and elastin fibers and the replacement of fibroblasts with myofibroblasts to contract the wound tissue. ${ }^{9}$ The healing process requires months for severe burns and results in scars or contractures, and healing may also be incomplete or require amputations.

Typically, clinical treatment of major burn injuries includes the stabilization of the patient, intravenous fluid administration, wound area cleaning, irrigation, removal of dead tissue and wound dressing applications, as required.,10,11 During the healing process, burn patients experience great pain. Analgesics to manage pain, antihistamines to combat wound itching and anxiety medications may be administered as required, and antibiotics are administered for burn injury wounds requiring surgical closure. ${ }^{12}$ Excessive or prolonged inflammation has been well documented to impair wound healing, ${ }^{\mathbf{1 3} 14}$ which increase the risk for the development of hypermetabolic states and associated muscle loss, shock and multiple organ dysfunction syndrome. ${ }^{15}$ Therefore, reducing excessive and maladaptive inflammatory responses while maintaining adaptive inflammatory responses to burn injury represents a significant challenge in burn wound healing care.

Nutrition has been documented to impact burn wound healing and recovery. ${ }^{\mathbf{1 6 , 1 7}}$ Gastrointestinal function disorder, which subsequently results in bacterial translocation, is also found in burn patients. ${ }^{18}$ In children, aggressive feeding is associated with decreased local tissue bacterial counts, sepsis rates and muscle protein catabolism. ${ }^{19}$ In adults, early nutritional support is correlated with shorter stays, accelerated wound healing, and decreased risk of infection. ${ }^{20}$ Dietary protein nutrients have been shown to play an important role in regulating inflammation. ${ }^{21}$ More specifically, in a randomized trial, nutritional supplements with isolated soy protein were observed to decreased inflammatory and oxidative stress responses and improve wound healing in burn patients. ${ }^{22}$ Nevertheless, there are still disadvantages to limit the development of isolated soy protein supplements, such as solubility and absorption. In addition, optimized soybean protein-derived peptides obtained by enzymatic hydrolysis and physical modifications, combined with ultrafiltration membrane separation and reversed micelle extraction of soybean proteins, ${ }^{23}$ may better regulate burn-induced inflammatory responses, due to the improved equilibrium of the essential amino acids, increased solubility, faster absorption rate and lower cost, and are more suitable for clinical oral nutritional supplementation (ONS). Small molecular peptides will rapidly provide protein to meet the needs of the body and represent a new, more practical and cost-effective approach to improve patient outcomes and quality of life. Thus, we have investigated the hypothesis that small molecular weight soybean protein-derived peptides can attenuate rat burn injury-induced inflammation and accelerate wound healing.

Our recently published paper provided compelling evidence that soybean protein-derived small molecular weight peptides nutrient supplementation under experimental conditions reduced muscle-specific UPS and autophagy. ${ }^{24}$ Considering the central role of inflammation in major burns and in the complex dynamics of burn wound healing, we further investigated the effect of soybean protein-derived small molecular weight peptides on burn-induced inflammation and wound healing. A rat model of major full-thickness burn $30 \%$ total body surface area (TBSA) injury ${ }^{25}$ with severity classification in accordance with the American Burn Association was employed to test the hypothesis of decreasing burn injury-induced inflammatory responses and improving burn wound healing. Four experimental groups were examined: (1) sham uninjured rats administered phosphate buffered saline (PBS) supplementation, (2) sham uninjured rats administered soybean protein-derived peptides supplementation, (3) burn-injured rats administered PBS supplementation and (4) burn-injured rats administered soybean protein-derived peptides supplementation.

The inflammatory response was evaluated on days 3, 7 and 14 postsham or burn injury, as measured by assessing systemic white blood cell (WBC) counts and the relative level of stimulated respiratory bursts, serum procalcitonin (PCT) and cytokine tumor necrosis factor- $\alpha$ (TNF- $\alpha$ ), chemokine C-C motif ligand 3 (CCL-3; also known as MIP-1 $\alpha$ ), chemokine $\mathrm{C}-\mathrm{C}$ motif ligand 11 (CCL-11; also known as eotaxin-1) and interleukin IL-10 (IL-10) levels. Local inflammatory responses were assessed in the cutaneous burn-injured wound tissue by immunohistochemical analysis of neutrophil and macrophage immune cell infiltration as measured by myeloperoxidase (MPO) and cluster of differentiation 68 (CD-68) expression. Relative cutaneous wound tissue measurements of the induction of proteins in the toll-like receptor 4/nuclear factor kappa-light-chain-enhancer of activated $\mathrm{B}$ (TLR-4/NF- $\mathrm{B}$ ) inflammatory cytokine signaling pathway were quantified by Western blot analysis. Burn injury wound size and healing were determined over an 8 week period after burn injury by biweekly measurement of the burn wound area between the wound margins. The angiogenesis protein marker of cluster of differentiation 31 (CD-31, also known as PECAM-1) expression in cutaneous tissues was also detected by immunohistochemical analysis.

\section{Materials and methods}

\section{Materials}

The materials and chemical characteristics of the optimized peptides used in this study were as follows: the peptides were 
kindly provided from Nutrily Biotechnology, Ltd. (Anyang, Henan, China) and prepared as previously outlined. ${ }^{\mathbf{2 4 , 2 6}}$ The antibodies were as follows: CD-68 (ab125212; Abcam, Cambridge, MA, USA), MPO (ab9535; Abcam, Cambridge, MA, USA), CD31 (ab182981; Abcam, Cambridge, MA, USA), normal goat serum (ab7481; Abcam, Cambridge, MA, USA), TLR4 (ab30667; Abcam, Cambridge, MA, USA), phospho-Ser536 NF- $\kappa \mathrm{B} / \mathrm{p} 65$ (\#3033; Cell Signaling Technology, Danvers, MA, USA), NF-кB/ p65 (\#8242; Cell Signaling Technology, Danvers, MA, USA) and $\beta$-actin (\#12620; Cell Signaling Technology, Danvers, MA, USA).

\section{Animal and experimental design}

All studies adhered to procedures consistent with the International Guiding Principles for Biomedical Research Involving Animals issued by the Council for the International Organizations of Medical Sciences (CIOMS) and were approved by the Institutional Animal Care and Use Committee at the First Affiliated Hospital of the PLA General Hospital. Six-week-old Wistar rats (230-290 g) from Peking University Laboratory Animal Centre were housed at room temperature $\left(22-24{ }^{\circ} \mathrm{C}\right)$ in 12 hour light/dark cycles. Rats were anesthetized by intraperitoneal injection of $2 \mathrm{~mL} \mathrm{~kg}{ }^{-1}$ body weight of a ketamine/ xylazine mixture $\left(7.5 \mathrm{~mL} 100 \mathrm{mg} \mathrm{mL} \mathrm{mL}^{-1}\right.$ ketamine (Parnell Laboratories, Auckland, New Zealand), $5.0 \mathrm{~mL} 20 \mathrm{mg} \mathrm{mL}$ ilium-xylazine-20 (Troy Laboratories, Sydney, Australia) and $7.5 \mathrm{~mL}$ MilliQ water (Millipore, Billerica, MA, USA)). Dorsal rat hairs were shaved with an electric razor, and the rats were divided randomly and equally into four groups: (1) sham injury + PBS supplementation, (2) sham injury + peptides supplementation, (3) burn injury + PBS supplementation and (4) burn injury + peptides supplementation. The 30\% TBSA thermal fullthickness third-degree burn injury model was previously established and described..$^{25}$ In brief, the back skins of the sham injury rat groups 1 and 2 were placed in $37{ }^{\circ} \mathrm{C}$ water for 12 seconds. In burn injury groups 3 and 4 , the back skins were placed in $94{ }^{\circ} \mathrm{C}$ water for 12 seconds. Immediately following injury, a balanced salt solution injection $\left(40 \mathrm{~mL} \mathrm{~kg}{ }^{-1}\right.$ body weight) was administered to prevent shock and 1\% tincture of iodine treatment was administered where the injured burn area was opened to the burn area to prevent infection. The rats in groups 1 and 3 were intragastrically administered $2 \mathrm{~mL} 1 \times$ PBS once a day, and groups 2 and 4 were intragastrically administered low molecular weight soybean protein-derived peptides ( $0.33 \mathrm{~g} \mathrm{~kg}^{-1}$ body weight) constituted in $2 \mathrm{~mL} 1 \times$ PBS.

\section{White blood cell count and respiratory burst activity analysis}

Routine whole blood white blood cell counts were completed in the clinical laboratory of the First Affiliated Hospital of the PLA General Hospital, as previously described. ${ }^{27}$ Respiratory burst activity was evaluated using $100 \mu \mathrm{L}$ of each whole blood sample following stimulation by the separate addition of $200 \mu \mathrm{L}$ PBS (control) and $1 \mu \mathrm{g} \mathrm{mL}{ }^{-1}$ propylene glycol methyl ether acetate (PMA). Then, $20 \mu \mathrm{L}$ of $0.1 \mathrm{mg} \mathrm{mL} \mathrm{mL}^{-1}$ dihydrorhodamine 123 (DHR-123) was added to each reaction tube, and the mixture was vortexed and incubated away from light at $37{ }^{\circ} \mathrm{C}$ for 30 minutes. After incubation, $3 \mathrm{~mL}$ precooled hemolysin was added to the samples and incubated for 5 minutes at room temperature to lyse the cells. The samples were then centrifuged at $500 \times g$ for 3 minutes, and the cells were subsequently collected. Cells were washed with $1 \times$ PBS. Fluorescence intensity was detected using flow cytometer analysis. The regions were drawn and the gates were set on neutrophils and monocytes, based on the forward and side light scattering. The mean fluorescence intensity was compiled for each population in the appropriate channel. In each case, a minimum of 1000 events per sample was collected to assure the accuracy of the measured result.

\section{PCT and cytokine measurements}

Rats from each group were euthanized on days 3, 7, or 14 after the injury protocol, and serum from each animal was collected. Serum PCT levels were detected using a rat PCT ELISA kit (CUSABIO, Wuhan, China) following the manufacturer's instructions. Rat Chemokine/Cytokine Panel 22plex (eBioscience, Vienna, Austria) was used to measure plasma cytokine concentrations of TNF- $\alpha$, CCL-3 (MIP-1 $\alpha$ ), CCL-11 (eotaxin-1) and IL-10 levels following the manufacturer's instructions and measured using a Luminex ${ }^{\mathrm{TM}} 200$ (Luminex, Shanghai, China).

\section{Immunohistochemical analysis}

On days 3,7 , and 14 , cutaneous tissue samples were collected from each group, fixed in $4 \%$ paraformaldehyde for 24 hours at room temperature, embedded in paraffin, sliced into $5 \mu \mathrm{m}$ thick perpendicular plane sections, deparaffinized in dimethylbenzene and rehydrated. Sections were incubated with specific antibodies against CD-68, CD-31 and normal goat serum followed the corresponding secondary antibody and peroxidase-anti-peroxidase (PAP) complex and then exposed to 3,3'-diaminobenzidine (DAB). The neutrophil and macrophage inflammatory cell infiltration was evaluated in 5 randomly selected fields of each slide, as previously described. ${ }^{28}$ Image Pro Plus 5.1 image analysis software (Media Cybernetics, Rockville, MD, USA) was employed to quantitatively analyze the expression levels of the MPO, CD-68, and CD-31 proteins. The primary antibody was replaced by goat normal serum for negative controls.

\section{Western blot analysis}

Total protein was extracted from the wounded skin tissue using a radioimmunoprecipitation assay (RIPA) lysis buffer (MACGENE, Beijing, China). The protein concentration was measured using a BCA Protein Assay Kit (Thermo Fisher Scientific, Shanghai, China). Approximately 30-60 $\mu \mathrm{g}$ total protein was examined by SDS-PAGE Western blot followed by antibody detection of TLR-4, phospho-Ser536 NF- $\kappa$ B/p65, NF$\kappa \mathrm{B} / \mathrm{p} 65$ and $\beta$-actin using the appropriate secondary antibodies and chemiluminescence detection, as previously described. ${ }^{29}$

\section{Cutaneous tissue wound healing measurements}

Photographs of the severe burn wounds were taken biweekly for 8 weeks to evaluate wound healing size and rates. Quantitative 
scalar measurements of the wound area using wound perimeter margins were measured using planimetry in the Image Pro Plus 5.1 image analysis software (Media Cybernetics, Rockville, MD, USA). TBSA $\left(\mathrm{cm}^{2}\right)$ was calculated as $9.83 \times W^{2 / 3}$, where $W=$ rat weight in grams. ${ }^{30}$ Relative burn wound extent (\% wound area $v s$. total initial burn-injured area) was calculated as [absolute wound area at a given time-point $\left(\mathrm{cm}^{2}\right) /$ total approximated initial burn-injured area $\left.\left(\mathrm{cm}^{2}\right)\right] \times 100$. Absolute wound healing $\left(\mathrm{cm}^{2}\right)$ was calculated as [initial 4 week wound area $\left(\mathrm{cm}^{2}\right)-$ wound area at a given time-point $\left.\left(\mathrm{cm}^{2}\right)\right]$, and relative wound healing (\% initial burn wound area) was calculated as [(initial 4 week wound area $\left(\mathrm{cm}^{2}\right)$ - wound area at a given time-point $\left.\left(\mathrm{cm}^{2}\right)\right)$ /initial wound area $\left.\left(\mathrm{cm}^{2}\right)\right] \times 100$. Relative wound healing progression in a specific time interval was calculated as current \% relative wound healing - previously defined timepoint $\%$ relative wound healing. Wound closure predictions were calculated based on the delayed exponential model outlined by Cukjatki et al. ${ }^{31}$ Under the conditions of this experiment, burn wounds did not display a delayed time phase of the wound healing process at the measured time points; therefore, $T_{\mathrm{DEX}}$ was considered to be negligible in this context. $S_{\mathrm{DEX}}$ (\% initial wound area) was calculated as [(wound area at a given time-point $\left(\mathrm{cm}^{2}\right) /$ initial 4 week wound area $\left.\left.\left(\mathrm{cm}^{2}\right)\right) \times 100\right]$ and plotted over time (days) and the $\varnothing_{\text {DEX }}$ time constant of the exponential function for each wound was calculated.

\section{Statistical analysis}

All data are expressed as the mean \pm standard deviation $( \pm \mathrm{SD})$ and were analyzed using an independent Student's $t$-test when comparing 2 groups, Wilcoxon signed-rank test for densitometric data and a factorial design ANOVA with Holm-Bonferroni method post hoc analysis for comparison among more than 2 groups $(\alpha=0.05)$. The differences were considered to be statistically significant at $p \leq 0.05$.

\section{Results}

\section{Soybean protein-derived peptides supplementation attenuate burn injury-induced leukocytosis}

Leukocytosis, an increase in the number of WBCs above the normal range, marks the activation of the immune system and indicates an inflammatory response. ${ }^{32}$ Neutrophils are an abundant type of WBCs that are activated during the acute phase of inflammation as one of the first inflammatory cells to migrate to a site of injury. Neutrophils function to protect the body by ingesting foreign particles and pathogens and dead or dying cells by releasing reactive oxygen species (ROS), superoxide, upon cell-surface activation to target these cells for phagocytosis and subsequent lysosomal degradation. ${ }^{33-35}$ The consumption of oxygen during the generation of reactive oxygen species is referred to as a respiratory burst, which has been assessed clinically for decades to determine the risk of nosocomial infections and innate immunity-related genetic disorders. $^{36,37}$ Thus, the quantification of the respiratory bursts is used as a metric of the innate ability of the immune system to protect the body from infections. Therefore, whole blood samples from heparinized experimental rats were collected and analyzed using flow cytometry with and without activation of oxidative respiratory burst by PMA stimulation. Leukocytosis was observed at days 7 and 14 following burn injury, with a 3-fold increase in WBC counts in the burn-injured rats compared with that in the sham rats administered PBS. The dietary administration of soybean protein-derived peptides produced a statistically significant reduction in the burn injuryinduced WBC count increases compared to PBS-treated rats at day 7 after the burn injury (18.6\%, Fig. 1A). The assessment of the neutrophil NADPH oxidase respiratory burst, as measured by the fluorescently labeled oxidation in neutrophil cells, following in vitro stimulation with PMA is shown in Fig. 1B. The unstimulated fluorescence is represented in red, while the PMAstimulated oxidative burst in neutrophils is represented in blue on the representative histograms, which were measured at days 3, 7 and 14 after sham or burn injury. Due to the individual differences and diverse treatments, the level of unstimulated fluorescence in each group is different. Thus, the relative level of stimulation index of respiratory burst was also measured and is presented in Fig. 1C. On day 3, the relative level of stimulation index of respiratory burst dramatically decreased in burninjured rat groups compared with that in the sham rat groups, which was consistent with a previous report that burn injury reduced neutrophil activation. ${ }^{38}$ However, on days 7 and 14 , there was an increase in the relative level of stimulation index of respiratory burst in the burn-injured rats administered soybean protein-derived peptides compared to the levels in all other treatment groups. In general, soybean protein-derived peptides supplementation dramatically elevated the respiratory burst ability of neutrophils in rats with burn injuries.

\section{Anti-inflammatory soybean protein-derived peptides supplementation expression profile}

The levels of inflammatory markers in circulating blood are often clinically used to assess the degree of systemic inflammation and predict the risk of septic shock. For example, the serum PCT level has become an important clinical marker as the levels correlate with the response to inflammatory stimuli. PCT serum concentration is currently considered the most sensitive and specific generally accepted clinical metric for evaluating the degree of severity of systemic inflammatory response induction. ${ }^{39-41}$ Inflammatory cytokines are small signaling proteins that produce effects that modulate the surrounding cells, where the effect of a particular cytokine on a given cell depends on the cytokine identity and concentration, the receptor expression and concentration and the activation of complementary or inhibitory signaling activity. ${ }^{42}$ The circulating blood levels of TNF- $\alpha$, produced primarily by activated macrophages and mast cells in the skin following trauma, ${ }^{\mathbf{4 3 , 4 4}}$ is also considered to be a quantitative measure of systemic inflammation and implicated in the production of the local heat, swelling and pain associated with inflammation and shock symptoms at extremely high concentrations. In addition to TNF- $\alpha$, CCL-3 (also known as MIP-1 $\alpha$ ) and CCL-11 (also known as eotaxin-1) are produced by activated macrophages and function to recruit additional WBCs to the site 
A

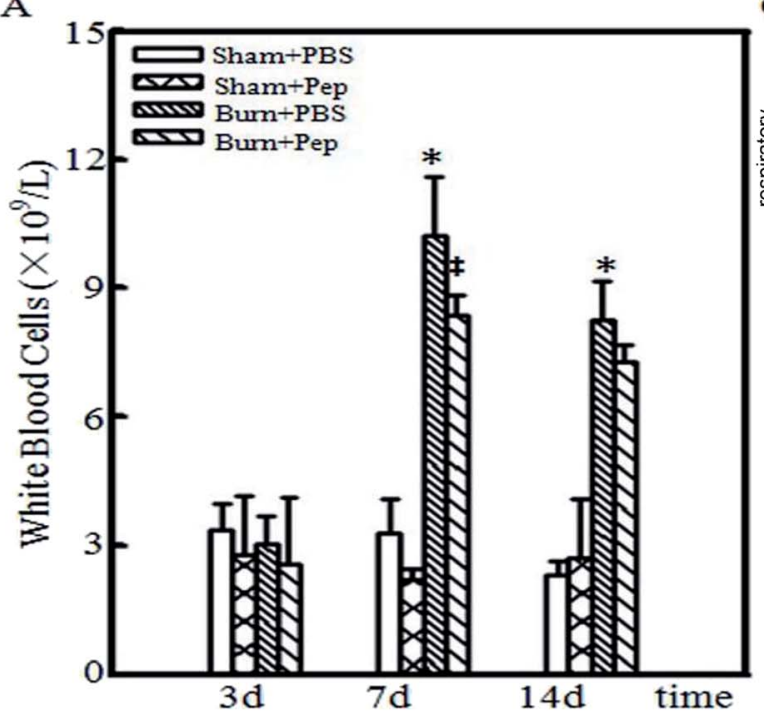

$\mathrm{C}$

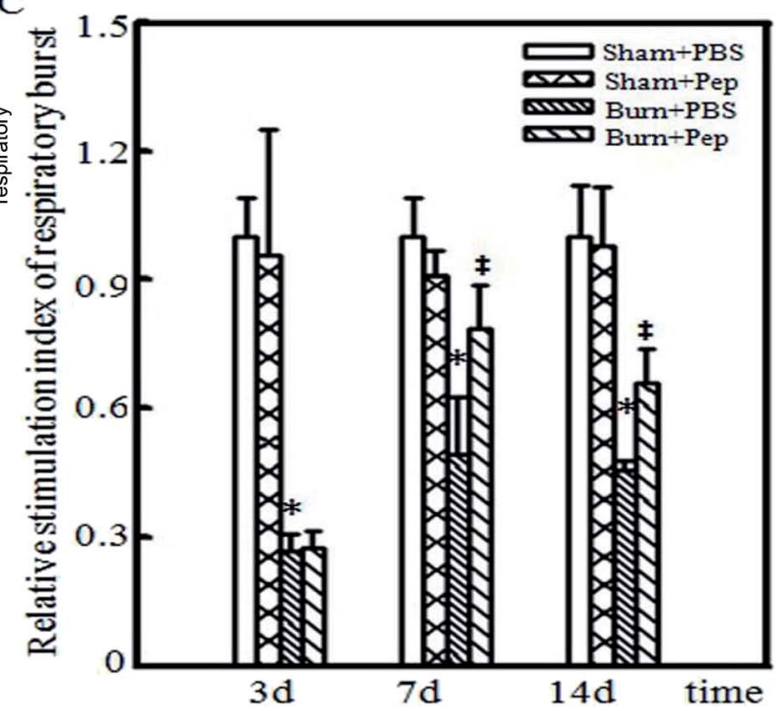

B

Sham+PBS

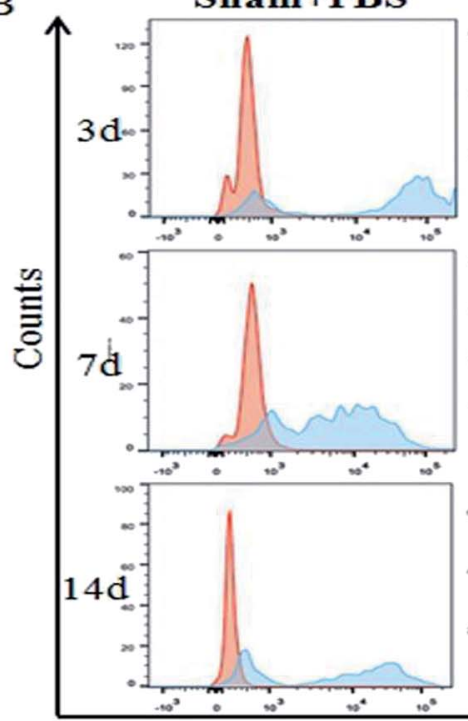

Sham+Pep

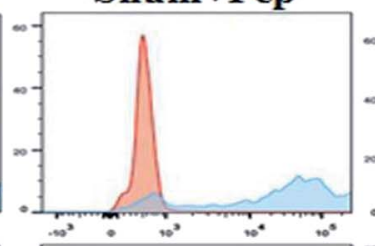

Burn+PBS

Burn +Pep
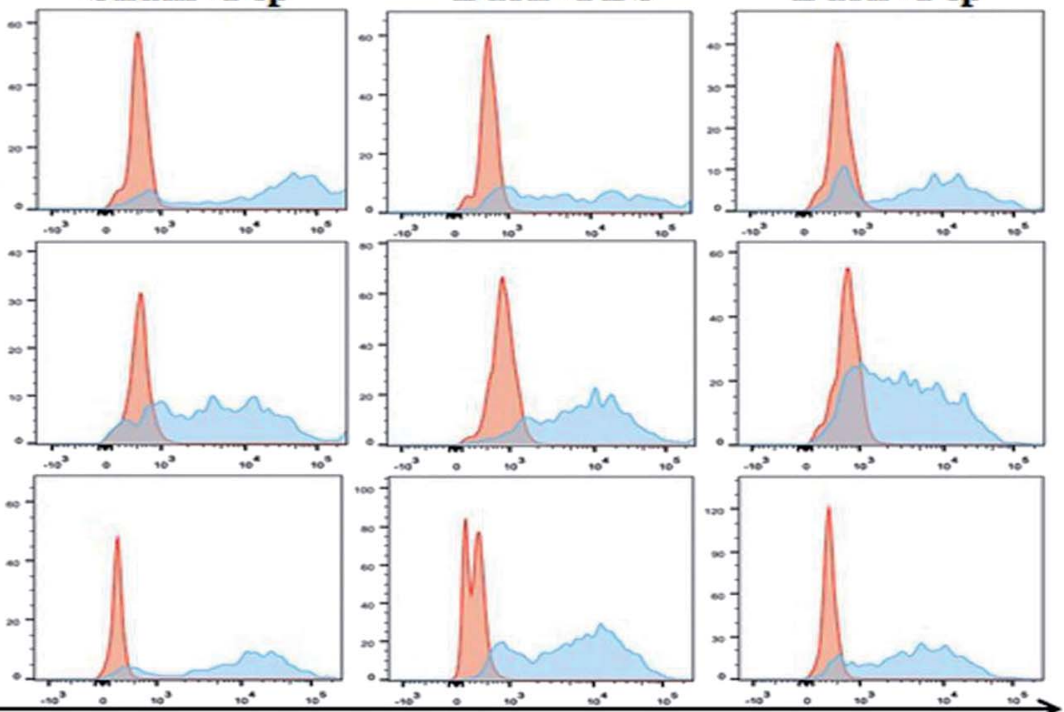

Fluorescence

Fig. 1 Soybean protein-derived peptides supplementation regulates burn-induced leukocytosis. (A) WBC counts of sham experimental group rats administered either PBS or soybean protein-derived peptides (sham + PBS and sham + peptides, respectively) and 30\% TBSA burn-injured rats administered either PBS or soybean protein-derived peptides (burn + PBS and burn + peptides, respectively), were determined 3, 7 and 14 days post-burn injury. (B) Induction of PMA-induced respiratory bursts in sham + PBS, sham + peptides, burn + PBS and burn + peptides experimental groups were also determined at 3, 7 and 14 days post-burn injury using flow cytometry detection of oxidation to fluorescent positive cells as compared to baseline fluorescence intensity in the same samples not treated with PMA. The unstimulated fluorescence was represented by the red histogram, while the PMA-stimulated oxidative burst in neutrophils was represented by the blue histogram as positive neutrophil counts. (C) The stimulation index (mean fluorescence intensity after PMA stimulation/mean fluorescence intensity of control) was measured. The star symbol $(*)$ indicates a significant difference between sham experimental group administered PBS and the $\$$ symbol represents a significant difference between burn-injured experimental group administered PBS (ANOVA, $p<0.05$ ).

of injury and induce the production of other inflammationpromoting cytokines, resulting in acute inflammation. ${ }^{45}$ Thus, CCL-3 also serves as an inflammatory protein marker and was assessed. CCL-11 is another important inflammatory cytokine that recruits eosinophils to the site of injury and is associated with the severity of allergic responses. ${ }^{46}$ High levels of CCL-11 have been described in several chronic inflammatory diseases, such as allergies, asthma, dermatitis rheumatoid arthritis and, more recently, periodontitis. ${ }^{47} \mathrm{CCL}-11$ has also been shown to predict the severity of atherosclerotic disease associated with vascular inflammation, with a high level of accuracy. ${ }^{48}$ The cytokine IL-10 has been associated with the counteraction of hyperactive inflammatory responses ${ }^{49}$ by inhibiting TNF- $\alpha$-converting enzyme, ${ }^{50}$ the production of inflammation-promoting cytokines and the secretion of interferon- $\gamma$ (IFN- $\gamma$ ) from TLR-activated cells. ${ }^{51-53}$ Therefore, the expression levels of PCT, TNF- $\alpha$, CCL-3, CCL-11 and IL-10 in the sham and burn rat groups at experimental days 3, 7 and 14 were measured. At days 3, 7, and 14 after 
burn injury, significantly higher production of PCT was measured in the PBS-administered rat treatment group compared to the sham treatment groups, peaking at day $7(20 \%$, $34 \%$ and $20 \%$ increase, respectively). However, the soybean peptides supplementation eliminated the burn injury-induced increase in PCT levels, resulting in PCT levels comparable to those of the sham, uninjured rats (Fig. 2A). In the PBSadministered rats, burn injury resulted in significantly higher TNF- $\alpha$ levels than that in the sham experimental groups at days 3 and 7 following burn injury (3-fold and 9-fold increase, respectively). However, the administration of peptides supplementation eliminated the burn injury-induced increase in TNF- $\alpha$ levels, resulting in TNF- $\alpha$ levels comparable to those of sham, uninjured rats at days 3 and 7 following burn injury (Fig. 2B). Similar results were obtained with the CCL-3 level analysis. Burn injury in the PBS-administered rats produced significantly higher CCL-3 levels than that in the sham experimental groups at days 3 and 7 following burn injury (1.6-fold and 3-fold, respectively). The soybean protein-derived peptides supplementation eliminated the burn injury-induced increase in CCL-3 levels, with CCL-3 levels comparable to that of uninjured rats at days 3 and 7 following burn injury (Fig. 2C). Burn injury in the rats administered PBS produced significant, 1.2-1.6-fold increases CCL-11 levels at days 3,7 and 14 following burn injury compared to
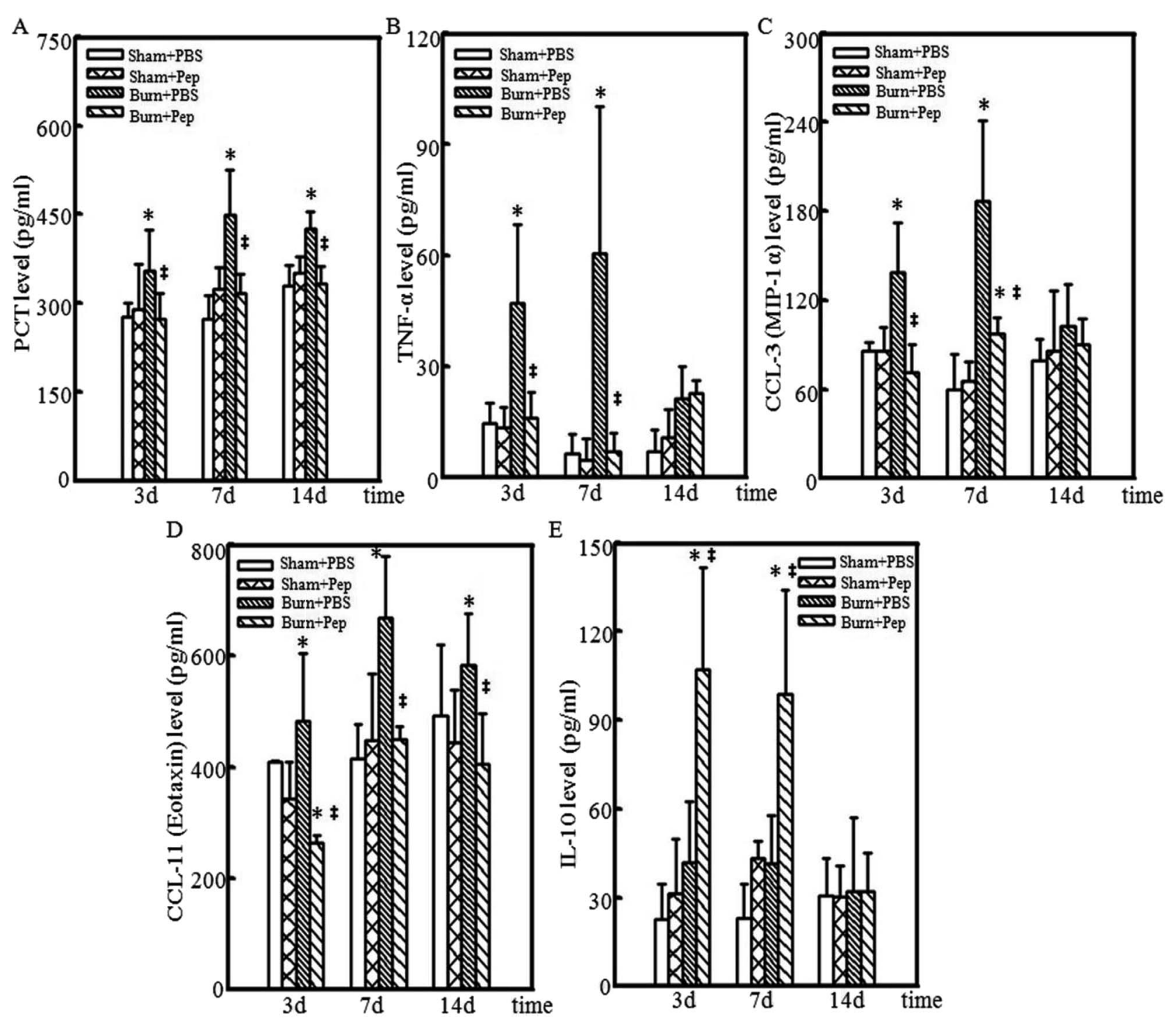

$\mathrm{E}$

Fig. 2 Soybean protein-derived peptides supplementation produced anti-inflammatory systemic burn injury-induced cytokine profile. Induction of systemic inflammatory markers were measured in sham experimental group rats administered either PBS or soybean protein-derived peptides (sham + PBS and sham + peptides, respectively) and 30\% TBSA burn-injured rats administered either PBS or soybean protein-derived peptides (burn + PBS and burn + peptides, respectively) at 3, 7 and 14 days post-burn injury. (A) Serum PCT levels were determined for each rat in each treatment group at the specified time-points using standard ELISA assay measurements. Inflammatory plasma protein cytokine levels were determined for each rat in each treatment group at the specified time-points using standard chemokine/cytokine Luminex TM assay measurements including (B) proinflammatory factor TNF- $\alpha,(C)$ chemokine CCL-3 (also known as MIP-1 $\alpha$ ), (D) chemokine CCL-11 (also known as eotaxin) and (E) anti-inflammatory cytokine IL-10, were shown. The star symbol (*) indicates a significant difference between sham experimental group administered PBS and the * symbol represents a significant difference between burn-injured experimental group administered PBS (ANOVA, $p<0.05$ ). 
that in sham groups, peaking at day 7. The soybean proteinderived peptides supplementation eliminated the burn injuryinduced increase in CCL-11 levels at all time points measured, with CCL-11 levels lower than or comparable to that of nonburn injured rats at days 3 and 7 following burn injury (Fig. 2D). In addition, burn injury in the PBS-administered rats produced IL10 levels that were not significantly different from the uninjured sham rat groups, whereas the administration of soybean protein-derived peptides in burn-injured rats resulted in a significant increase in IL-10 levels at days 3 and 7 following burn injury compared to that of burn-injured rats administered PBS (2.6-fold and 2.4-fold, respectively) (Fig. 2E). Taken together, these results indicated an anti-inflammatory effect of peptides nutrient supplementation in response to burn injury.

\section{Soybean protein-derived peptides supplementation reduce burn injury-induced cutaneous immune cell infiltration}

In addition to systemic inflammatory markers, the local response of burn wound tissue was evaluated. Neutrophil WBCs function to directly engulf foreign particles and dead or dying cells, prominently amplify inflammatory reactions by the release of cytokines, and recruit and activate other immune cells to assist in the removal of pathogens and damaged cells. However, neutrophil activity can cause oxidative damage to the normal tissue surrounding the site of injury. Neutrophils are currently known to be one of the first inflammatory cell types at a site of injury, migrating to the site of injury within minutes of trauma where they are reported to survive for 1-2 days. ${ }^{54} \mathrm{MPO}$ is a cellular protein that is abundantly expressed in neutrophil granulocytes ${ }^{\mathbf{5 5}}$ and used immunohistochemically as a neutrophil cell marker. Macrophages are another type of differentiated white blood cell with an essential role in the stimulation of burn injury-induced inflammation and immune response. Neutrophils stimulate macrophage recruitment to the site of injury, where they specialize in the removal of damaged cells and foreign pathogens by phagocytosis, including the neutrophils themselves. Macrophages also secrete proteases to remove dead, damaged or infected tissue and a number of cytokines, recruiting other immune cells to the site of injury. ${ }^{56}$ Macrophages can be identified by their specific cell-surface expression of the glycoprotein CD-68. ${ }^{57}$ Accordingly, the immunohistochemical detection of MPO and CD-68 in sham and burninjured cutaneous tissue samples from each experimental group were harvested for analysis to determine the effect of the administration of peptides nutrient supplementation on the local inflammatory neutrophil and macrophage infiltration response to burn injury at 3, 7 and 14 days following burn trauma. The burn injury induced an increase in MPO-positive stained cells at day 3 in the PBS-treated rats, whereas the burn-injured rats administered peptides had no appreciable increases in MPO-positive cells at day 3 compared to that of the uninjured treatment group. The burn injury response was followed by a more dramatic increase in the number of MPOpositive stained cells on days 7 and 14, which was significantly attenuated but not completely prevented in the burninjured rat group administered peptides (Fig. 3A). Similar results were obtained in the CD-68 immunohistochemical analysis (Fig. 3B). Negative controls (primary antibody replaced by goat normal serum) were used to reflect the specific reaction of the MPO and CD-68 antibodies. The relative MPO and CD-68 protein expression was also evaluated, and the results were consistent with the results shown by the relative immunohistochemical analysis (Fig. 3C and D). These results indicated a dramatic reduction in the burn injury-induced cutaneous local infiltration of neutrophils and macrophages at all measured time points following the administration of soybean protein-derived peptides supplementation.

\section{Soybean protein-derived peptides supplementation attenuate the local induction of the TLR-4/NF- $\mathrm{B}$ signaling pathway}

TLR-4 is a transmembrane protein that plays a key role in regulating the inflammatory response by controlling the activation of $\mathrm{NF}-\kappa \mathrm{B}$ gene transcription and stimulation of the production of inflammatory cytokines. ${ }^{58-60}$ Known human TLR4 gene polymorphisms have been associated with increased IL10 production and decreased pro-inflammatory cytokines. ${ }^{61}$ In addition, our previous work demonstrated that miR-181c inactivated the TLR-4/NF- $\mathrm{B}$ signaling pathway induced by inflammatory macrophages, resulting in the attenuation of burninduced inflammation. ${ }^{62}$ In addition to TLR-4 activation, the phosphorylation of the transcription factor NF- $\kappa B$ p65/RELA plays a key role in regulating $\mathrm{NF}-\kappa \mathrm{B}$ activation and function by generating site-specific posttranslational modifications to further enhance NF- $\kappa \mathrm{B}$ function as a transcription factor. ${ }^{63} \mathrm{NF}-$ $\kappa \mathrm{B}$ p65/RELA knockout mice have lymphocyte activation failure resulting in embryonic lethality due to liver apoptosis, suggesting an indispensable role of NF- $\kappa$ B p65/RELA in immune system development, which not observed with other family member gene deletions. ${ }^{64}$ Thus, the effect of peptides nutrient supplementation on key regulators of the NF- $\kappa \mathrm{B}$ transcription and inflammatory response signaling cascades was determined by Western blot analysis of the TLR- $4, \beta$-actin, phospho-NF- $\kappa \mathrm{B}$ p65/RELA (p-p65) and total NF- $\kappa B$ p65/RELA (p65) proteins in cutaneous tissue samples from the sham-treated and burninjured rat groups with and without soybean protein-derived peptides supplementation on day 3 following burn injury (Fig. 4A). The TLR-4 protein levels were normalized to $\beta$-actin protein expression levels, and the phosphorylated NF- $\kappa \mathrm{B}$ р65/ RELA levels were normalized to total NF- $\kappa$ B p65/RELA protein expression. The burn-injured wound tissues from the rats administered PBS were determined to have significantly higher relative TLR-4 protein expression levels (4-fold) and phosphoNF- $\kappa$ B p65/RELA activation (2-fold) than uninjured rat. This effect was attenuated by the administration of soybean proteinderived peptides nutrient supplementation; a 56\% TRL-4 relative expression reduction and 55\% reduction in relative phospho-NF- $\kappa$ B p65/RELA activation was observed in the burninjured rats administered the supplement (Fig. 4B). These findings suggested that the peptides reduced the burn injuryinduced activation of the NF- $\mathrm{B}$ transcriptional signaling pathways, which is likely a mechanism of action connected to the observed anti-inflammatory profile. 

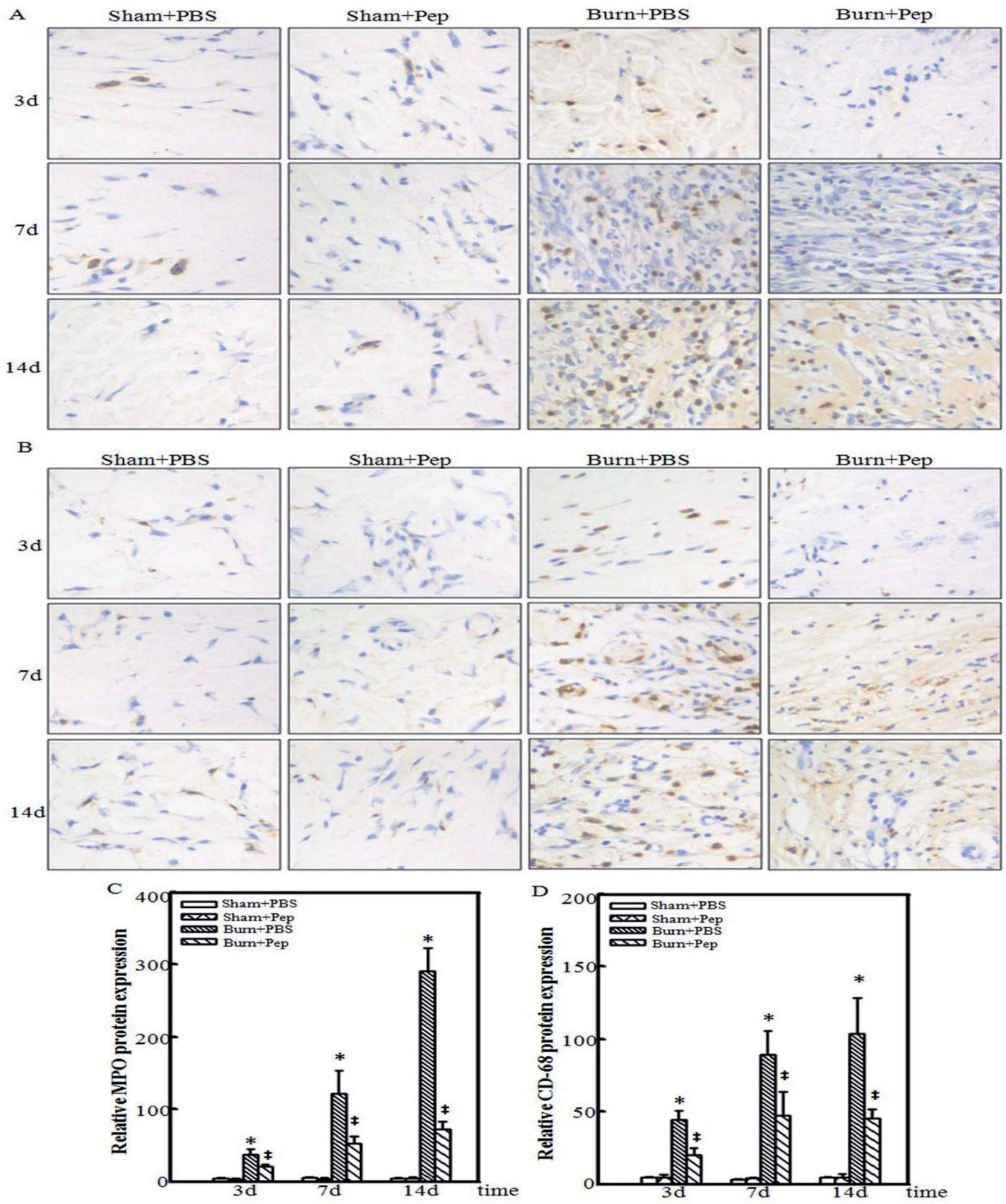

Fig. 3 Soybean protein-derived peptides supplementation inhibited local burn injury-induced inflammatory immune cell infiltration. Induction of local inflammatory immune cell infiltration of neutrophils and macrophages at the site of burn injury was evaluated in cutaneous fixed tissue section slices by immunohistochemical analysis using the (A) neutrophil cellular marker MPO and the (B) macrophage cellular marker CD-68 in sham experimental group rats administered either PBS or soybean protein-derived peptides (sham + PBS and sham + peptides, respectively) and 30\% TBSA burn-injured rats administered either PBS or soybean protein-derived peptides (burn + PBS and burn + peptides, respectively) 3 days post-burn injury. And the enlargement scale of each image was 400 times. The quantitative analysis of MPO (C) and CD-68 (D) in different groups was measured by Image Pro Plus software.

\section{Soybean protein-derived peptides supplementation accelerate wound healing}

The TBSA for all rats was calculated at the time of sham or burn injury and there was no statically significant difference between groups ( $399 \pm 9 \mathrm{~cm}^{2}$ sham + PBS; $414 \pm 14 \mathrm{~cm}^{2}$ sham + peptides; $393 \pm 15 \mathrm{~cm}^{2}$ burn + PBS; $394 \pm 20 \mathrm{~cm}^{2}$ burn + peptides). The $30 \%$ TBSA of rats was calculated to represent approximately a $118 \mathrm{~cm}^{2}$ burn injury area in both burn-injured study groups. 
A

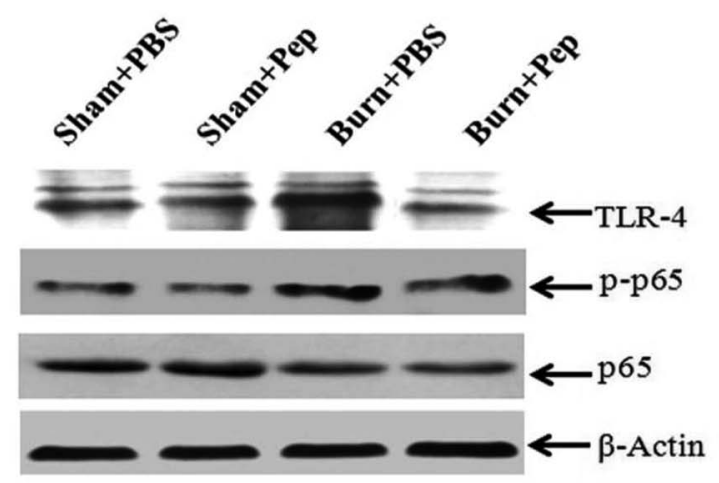

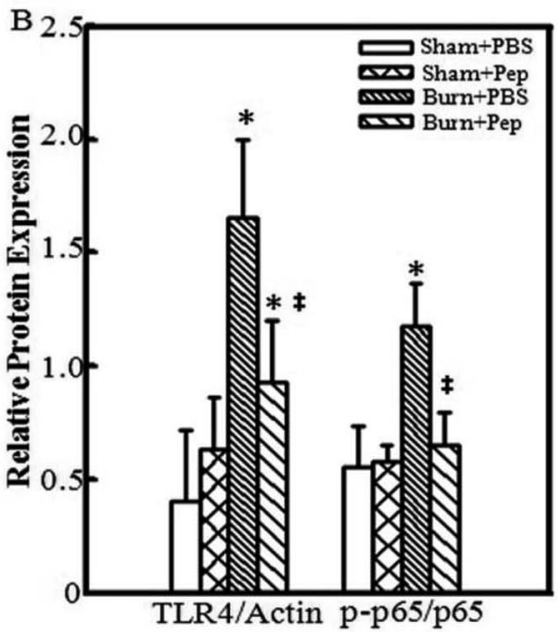

Fig. 4 Soybean protein-derived peptides supplementation reduced burn injury induction of TLR-4/NF- $\kappa$ B inflammatory signaling pathway. Induction of the TLR-4/NF- $\kappa B$ inflammatory signaling pathway at the site of burn injury was evaluated in total protein extract of cutaneous tissue by western blot analysis following protein concentration determinations. (A) Equal total protein concentrations of each sample were loaded for gel-electrophoresis and protein expression levels were detected using TLR-4, $\beta$-actin, phospho-NF- $\kappa B$ p65/RELA and total NF- $\kappa B$ p65/RELA specific antibodies followed by appropriate secondary antibody via chemiluminescent evaluation in sham experimental group rats administered either PBS or soybean protein-derived peptides (sham + PBS and sham + peptides, respectively) and 30\% TBSA burn-injured rats administered either PBS or soybean protein-derived peptides (burn + PBS and burn + peptides, respectively) 3 days post-burn injury. (B) Image $J$ software densitometry measurements were used to quantify the western blot analysis protein expression and analyzed using Wilcoxon signed-rank test and relative protein expression levels were calculated normalizing TRL-4 expression to that of $\beta$-actin and phospho-NF- $\mathrm{B}$ p $65 / \mathrm{RELA}$ to that of total NF- $\kappa B$ p65/RELA. The star symbol $(*)$ indicates a significant difference between sham experimental group administered PBS and the * symbol represents a significant difference between burn-injured experimental group administered PBS (ANOVA, $p<0.05)$.

Pictures and wound area measurements at the site of injury were taken immediately prior to burn injury trauma and every 2 weeks for 8 weeks following the burn injury (Fig. 5A). While descriptive burn injury and wound appearance observations such as the surrounding skin color, peripheral tissue edema and induration, epithelialization and the presence of exudates were recorded, these features were notably variable and unreliable at predicting burn injury wound healing progression. Furthermore, they are complex to assess in the context of quantitative burn injury wound outcome metrics and therefore were not further analyzed in the scope of this study. The relative burn wound extent was calculated at the manifestation of burn wounds and at 4,6 and 8 weeks thereafter. The relative burn wound extent was significantly smaller in the burn-injured rats administered soybean protein-derived peptides compared to that of burn-injured rats administered PBS (Fig. 5B; 22\%, 28\% and $57 \%$ smaller burn wounds relative to burn-injured areas at 4,6 and 8 weeks, respectively). The absolute wound healing was calculated $\left(\mathrm{cm}^{2}\right)$ at weeks 6 and 8 based on the initial wound size measured at week 4 and expressed as relative wound healing ( $\%$ total wound healed). The PBS-treated burn-injured rats had a $37.7 \pm 5.7 \%$ wound healing rate at week 6 and 40.6 $\pm 4.0 \%$ at week 8 . However, the burn-injured rats administered soybean protein-derived peptides had a greater relative wound healing rate of $42.6 \pm 7.7 \%$ at week 6 and a statistically higher rate of $66.8 \pm 7.2 \%$ at week 8 (Fig. 5C). Wound closure can be predicted with a high degree of accuracy $(p=0.900)$ after 6 weeks using a delayed exponential wound healing model, ${ }^{64}$ where wound closure is defined as the mathematically predicted wound area of $<5 \%$ the initial wound area and $<1 \mathrm{~cm}^{2}$; thus, this model was used for this experiment since the wounds were not closed at the end of the observation period allotted within the scope of this study. A delayed wound healing phase dynamic for the burn wounds under the conditions of this experiment was not observed. Nonlinear burn injury healing outcome trajectories were modeled as the relative burn wound extent plotted over time, and wound closure was calculated. Burn-injured rats administered PBS had a calculated wound closure of $17.2 \pm 1.9$ weeks, whereas the burn-injured rats administered soybean protein-derived peptides were calculated to have wound closure at $9.1 \pm 1.3$ weeks (Fig. 5D), representing an 8 week improvement in healing time or a $47 \%$ reduction in healing time to wound closure of $30 \%$ TBSA burn injury. Angiogenesis plays a critical role in wound healing, and CD-31 is an important marker of angiogenesis. The expression of CD31 in the cutaneous tissue of burn-treated rats administered soybean protein-derived peptides or PBS was quantified (Fig. 5E). The quantitative analysis indicated that the protein level of CD-31 was significantly increased in the rats administered soybean protein-derived peptides (Fig. 5F). The protein level of CD-31 was significantly increased in the rats administered soybean protein-derived peptides. In general, the soybean protein-derived peptides supplementation could enhance wound healing by suppressing inflammatory cell infiltration and promoting angiogenesis.

\section{Discussion}

These data provided compelling evidence that supplementation with soybean protein-derived small molecular weight peptides 
A

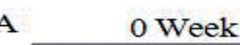

2 Weeks

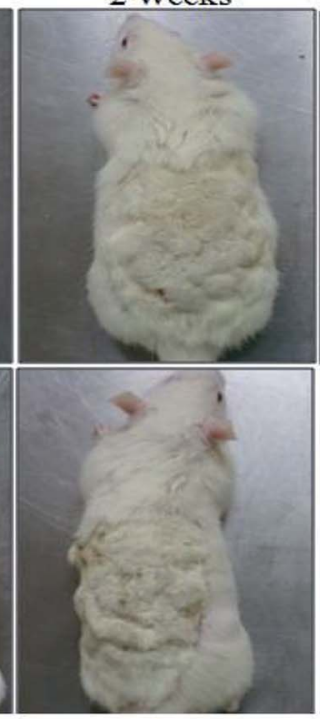

4 Weeks

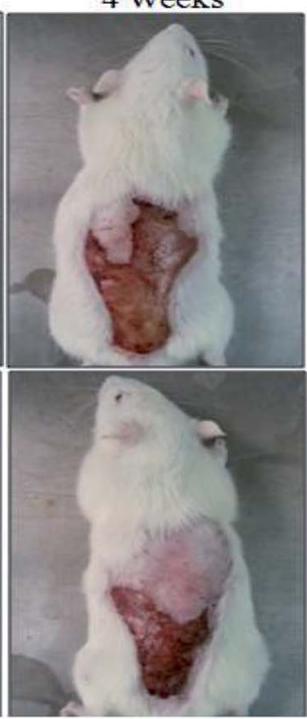

6 Weeks

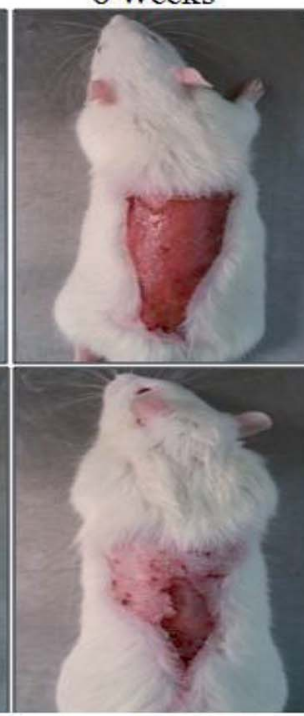

8 Weeks

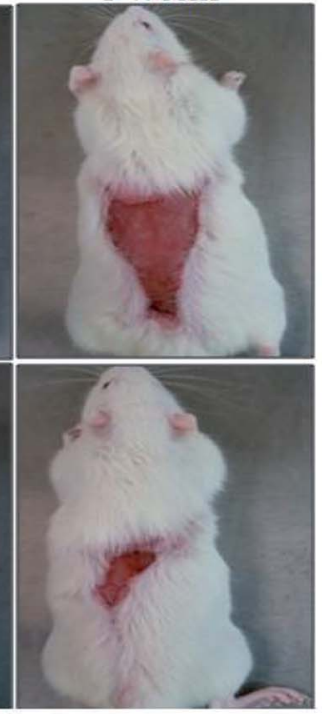

D
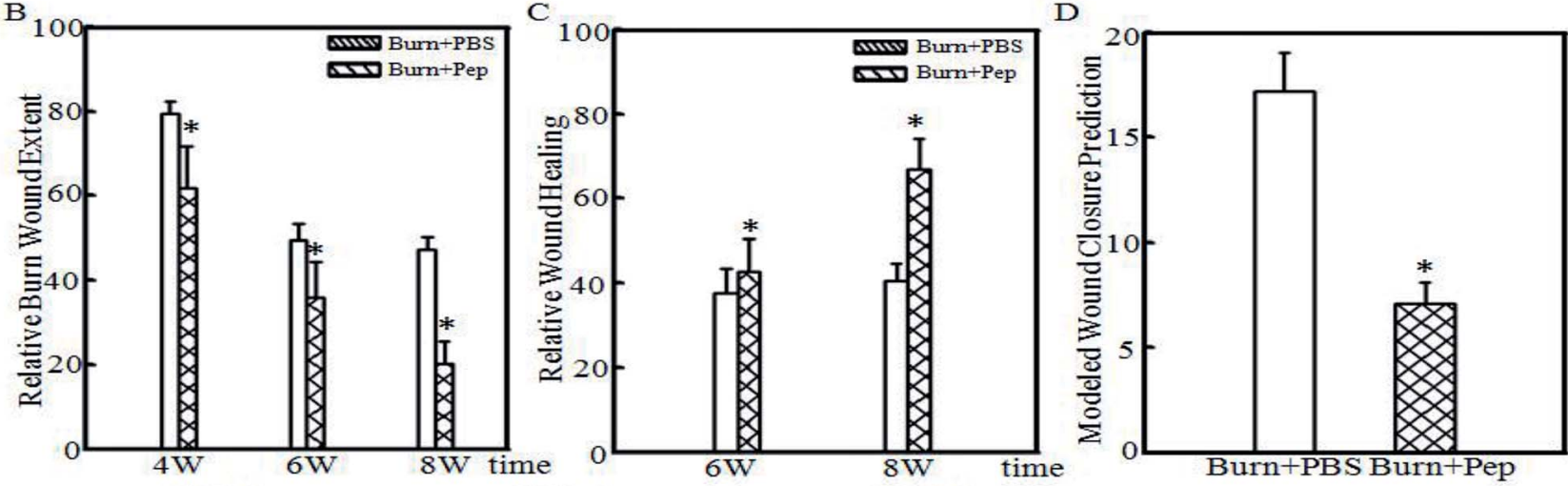

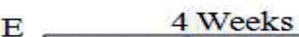

6 Weeks

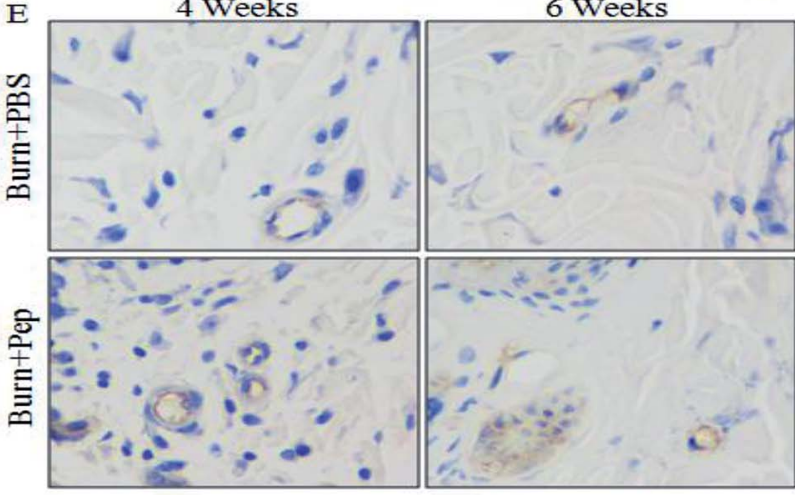

8 Weeks

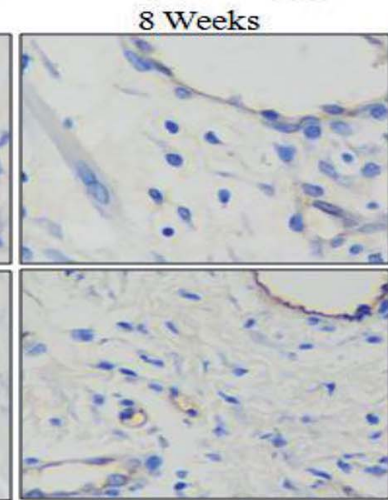

Burn+PBS Burn+Pep

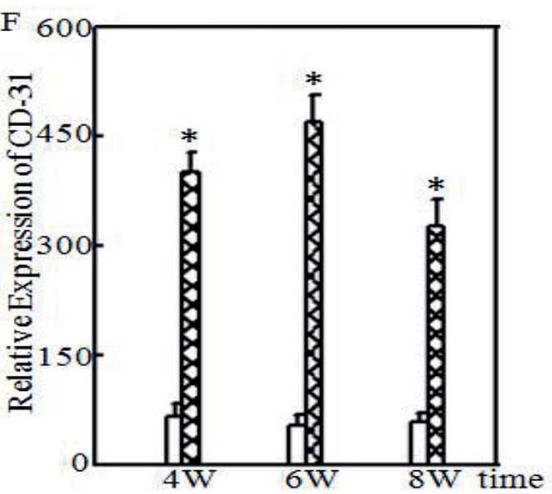

Fig. 5 Soybean protein-derived peptides supplementation promotes burn injury wound healing. (A) Injury area and wounds resulting from $30 \%$ TBSA burn injury were photographically captured in rats administered either PBS or soybean protein-derived peptides (burn + PBS and burn + peptides, respectively) immediately before burn trauma induction (week 0), 2, 4, 6 and 8 weeks post-burn injury. Quantitative scalar measurements of the burn wound area were measured $\left(\mathrm{cm}^{2}\right)$ using Image-Pro Plus 5.1 software. (B) Relative burn wound extent (\% wound area of total burn injured-area) was calculated as the absolute wound area $\left(\mathrm{cm}^{2}\right)$ at either 4,6 or 8 weeks post-injury/total approximated initial burninjured area $\left(\mathrm{cm}^{2}\right) \times 100$; (C) relative burn wound healing (\% healed wound area of total wound) was calculated as (initial 4 week wound area $\left(\mathrm{cm}^{2}\right)$ - wound area at a either 6 or 8 weeks post-injury $\left(\mathrm{cm}^{2}\right) /$ initial wound area $\left.\left(\mathrm{cm}^{2}\right)\right) \times 100$; (D) exponential wound healing model wound closure predictions were projected. (E \& F) CD-31, the marker of angiogenesis, was used to reveal the angiogenesis of burn wound (E) and quantitative analysis was done (F) at indicated groups. The star symbol $(*)$ indicates a significant difference between burn injured rats administered PBS versus soybean protein-derived peptide (Student's t-test; $p<0.05$ ).

reduced the local and systemic inflammatory responses, cutaneous immune cell infiltration, local induction of the TLR-4/NF$\kappa \mathrm{B}$ signaling pathway, and the initial size of burn wounds induced by major $30 \%$ TBSA full-thickness burn injury and accelerated the speed of burn wound healing in a rat model. As such, dietary supplementation of soybean protein-derived small 
molecular weight peptides in humans represents novel and attractive potential for adjunctive burn injury treatment to reduce excessive inflammatory responses, accelerate wound healing and improve burn injury outcomes.

Although the degree of functional recovery of the burninjured tissues was not assessed within the scope of this study, it would be interesting to determine whether supplementation with soybean protein-derived peptides results in an enhanced ability to reduce scar tissue and increase the recovery of functional dermal tissue blood and lymph vessels, further increasing the long-term value by potentially decreasing morbidity and improving functional outcomes. In addition, considering the impact of peptides supplementation on increased local and systemic burdens, such as in the presence of local infectious agents or other body infections that are not at the specific site of injury, would provide additional information relevant to burn-injured patient presentations. ${ }^{65}$

In addition to the promising results of this study, this research supports the substantial and underappreciated potential of deriving treatment outcome enhancements through the optimization of practical and cost-effective functional supplements. While it is unlikely that medical nutrition therapy as a standalone treatment will provide adequate potency to sufficiently replace current medical practice treatment standards in many disease states, harnessing foodderived biological activities has appealing potential for use as an adjunctive therapeutic options to control or prevent diseases, ameliorate side effects, reduce the risk of developing disease complications, decrease the prevalence of comorbidities and promote good health. The potential impact of such solutions is vast, as the development of efficacious functional supplements, designed to have physiological benefits and/or reduce the risk of disease states, can add tremendous therapeutic value and are also cost-effective and practical to implement.

In fact, support for the important role of dietary supplementation has been documented; unhealthy dietary nutrition has been linked to the development, aggravation or promotion of disease progression of many medical conditions, reinforcing this assertion. ${ }^{66,67}$ However, the optimization of existing nutrients to provide the desired physiological benefits and the scientific efficacy of such interventions is lacking. As the availability of knowledge continues to expand, innovative research should not only address the development of efficacious treatments and therapeutics but also adopt a more holistic approach towards solving health care problems by focusing on the development of practical solutions within the applicable circumstantial framework that the problem presents. As such, it is pragmatic to consider the optimization of one of the most fundamental provisional requirements for the maintenance of life-nutrition. As a good natural resource of vegetable protein, soybean protein has been applied to many aspects of the food industry due to its high nutritional value. However, the solubility and absorption of soybean protein has limited further development. As described in the previous study ${ }^{24}$ after enzymatic treatment combining an ultrafiltration membrane and metal film separation, soybean protein isolate (SPI) was degraded into small molecular weight peptides with excellent solubility and fast absorption, which was more suitable for ONS clinically.

Up to one-third of burn injuries in low income countries may be treated the application of materials such eggs, mud, leaves or cow fecal matter; ${ }^{9}$ therefore, the development of expensive wound care dressings or treatment options requiring the need for surgical or specialized medical professional care would limit the practical implementation of these solutions in the populations most afflicted by burn injuries due to insufficient financial resources and availability of such treatment options. Optimized functional supplement options to improve outcomes represent a more practical solution.

Currently, the development of health and wellness solutions is attractive to more researchers, and developing simple lowcost solutions is an important investment to accelerate the global economy and contribute to human development. Although good health increases the economic productivity of individuals and the economic growth rate of countries, ${ }^{68}$ every countries could benefit the development of simple cost-effective health and wellness improvement interventions, as the struggle of controlling health expenditures and making health care accessible to the broad population are ubiquitous problems. Optimized interventions with functional supplements could represent a key opportunity to help individuals take personal control over improving their own health and reduce the burden of care of health care providers.

Thus, we hope that this work not only contributes to improving burn patient outcomes but also more broadly encourages the further exploration and establishment of the scientific efficacy of functional supplements and the governmental prioritization and support of this exploration. Most importantly, scientific investigations of functional supplements have led to significant contributions in decreasing global human morbidity and mortality and improving health, wellness and productive lifespan.

\section{Conclusions}

Our results showed that soybean protein-derived small molecular weight peptides mitigated the major severe full-thickness burn injury-induced inflammatory response by modulating the local induction of the TLR4/NF- $\mathrm{KB}$ inflammatory signal pathway, the infiltration of neutrophil and macrophage inflammatory mediators at the site of injury, and the production of systemic white blood cells, the pro-inflammatory cytokines TNF- $\alpha$, CCL-3 and CCL-11 and the anti-inflammatory cytokine IL-10 levels in a rat model. The supplementation with soybean protein-derived small molecular weight peptides resulted in smaller initial 30\% TBSA rat burn wounds and improved burn injury wound healing rates with a predicted $47 \%$ acceleration in wound closure healing time. This study provided novel evidence that nutrient supplementation with soybean protein-derived peptides could decrease the inflammatory response and improve burn injury outcomes. Furthermore, these results implicated the use of soybean protein-derived peptides supplements as a practical and cost-effective intervention that is 
easily administered without requiring a skilled medical professional for the treatment of severe burn injuries, to potentiate improved outcomes and to help to reduce the cost of care burden, morbidity and mortality rates for these patients.

\section{Conflicts of interest}

The authors declare no conflict of interest.

\section{Abbreviations}

$\begin{array}{ll}\text { TBSA } & \text { Total body surface area } \\ \text { WBC } & \text { White blood cell } \\ \text { PCT } & \text { Procalcitonin } \\ \text { TNF- } \alpha & \text { Tumor necrosis factor-alpha } \\ \text { CCL-3 } & \text { Chemokine (C-C motif) ligand } 3 \\ \text { CCL-11 } & \text { Chemokine (C-C motif) ligand 11 } \\ \text { IL-10 } & \text { Interleukin-10 } \\ \text { MPO } & \text { Myeloperoxidase } \\ \text { CD-68 } & \text { Cluster of differentiation } 68 \\ \text { NF- } \kappa \text { B } & \text { Nuclear factor kappa-light-chain-enhancer of activated B } \\ \text { TLR-4 } & \text { Toll-like receptor 4 } \\ \text { CD-31 } & \text { Cluster of differentiation } 31 \\ \text { ONS } & \text { Oral nutritional supplement } \\ \text { ROS } & \text { Reactive oxygen species } \\ \text { IFN- } \gamma & \text { Interferon-gamma }\end{array}$

\section{Acknowledgements}

We thank Dr Rebecca Scotland for her assistance in writing of this manuscript. The study was supported by grants from the National Key Research and Development Program of China (2016YFD0400401), the Beijing Nova Program (Z181100006218043), the National Natural Science Foundation of China (NSFC81471873), the Beijing Natural Science Foundation (7172210), and the Research Foundation for Youth Scholars of Beijing Technology and Business University (QNJJ2015-25).

\section{Notes and references}

1 World Health Organization, Global health estimates 2015: Disease burden by cause, age, sex, by country and by region, 2000-2015, Geneva, 2016.

2 GBD 2015 Disease and Injury Incidence and Prevalence Collaborators, Lancet, 2016, 388, 1545-1602.

3 B. A. Pruitt Jr, S. E. Wolf and A. D. Mason Jr, in Total Burn Care, W.B. Saunders, London, 4th edn, 2012, pp. 15-45.e14.

4 J. Tintinalli, Emergency Medicine (Tintinalli), New York, 2010, pp. 1374-1386.

5 I. Sahin, S. Ozturk, D. Alhan, C. Acikel and S. Isik, Ann. Burns Fire Disasters, 2011, 24, 9-13.

6 J. Q. Tan, H. H. Zhang, Z. J. Lei, P. Ren, C. Deng, X. Y. Li and S. Z. Chen, Burns, 2013, 39, 1551-1556.

7 A. J. Singer, S. A. McClain, B. R. Taira, J. L. Guerriero and W. Zong, Acad. Emerg. Med., 2008, 15, 549-554.
8 S. Werner, T. Krieg and H. Smola, J. Invest. Dermatol., 2007, 127, 998-1008.

9 V. K. Tiwari, Indian J. Plast. Surg., 2012, 45, 364-373.

10 S. Enoch, A. Roshan and M. Shah, Br. Med. J., 2009, 338, b1037.

11 S. Hettiaratchy and R. Papini, Br. Med. J., 2004, 329, 101-103.

12 R. L. Sheridan and R. G. Tompkins, in Total Burn Care, W.B. Saunders, London, 4th edn, 2012, p. 664.

13 D. W. Edgar, J. S. Fish, M. Gomez and F. M. Wood, J. Burn Care Res., 2011, 32, 334-347.

14 K. Sommer, A. L. Sander, M. Albig, R. Weber, D. Henrich, J. Frank, I. Marzi and H. Jakob, PLoS One, 2013, 8, e73992.

15 L. Zeng, J. Du, W. Gu, A. Q. Zhang, H. Y. Wang, D. L. Wen, L. Qiu, X. T. Yang, J. H. Sun, M. Zhang, J. Hao and J. X. Jiang, Crit. Care, 2015, 19, 6.

16 H. Andel, L. P. Kamolz, K. Horauf and M. Zimpfer, Burns, 2003, 29, 592-595.

17 A. Abdullahi and M. G. Jeschke, Nutr. Clin. Pract., 2014, 29, 621-630.

18 L. J. Magnotti and E. A. Deitch, J. Burn Care Rehabil., 2005, 26, 383-391.

19 D. W. Hart, S. E. Wolf, D. L. Chinkes, R. B. Beauford, R. P. Mlcak, J. P. Heggers, R. R. Wolfe and D. N. Herndon, J. Trauma, 2003, 54, 755-761; discussion 761-754.

20 M. J. Mosier, T. N. Pham, M. B. Klein, N. S. Gibran, B. D. Arnoldo, R. L. Gamelli, R. G. Tompkins and D. N. Herndon, J. Burn Care Res., 2011, 32, 104-109.

21 M. S. Da Silva and I. Rudkowska, Mol. Nutr. Food Res., 2015, 59, 1249-1263.

22 S. Babajafari, M. Akhlaghi, S. M. Mazloomi, M. Ayaz, A. Noorafshan, P. Jafari and A. Hojhabrimanesh, Burns, 2018, 44, 140-149.

23 B. F. Gibbs, A. Zougman, R. Masse and C. Mulligan, Food Res. Int., 2004, 37, 123-131.

24 F. Zhao, Y. Yu, W. Liu, J. Zhang, X. Liu, L. Liu and H. Yin, J. Agric. Food Chem., 2018, 66, 2724-2734.

25 Y. Yu, J. Chai, H. Zhang, W. Chu, L. Liu, L. Ma, H. Duan, B. Li and D. Li, Shock, 2014, 42, 578-584.

26 X. Q. Liu and R. L. L. T. Scotland, US Pat., 20170156369, 2017.

27 L. Liu, X. Li, J. Yang, J. Chai, Y. Yu, H. Duan, H. Song, R. Feng, T. Wang, H. Yin, Q. Hu, S. Wang and J. Du, Int. J. Clin. Exp. Pathol., 2015, 8, 6367-6376.

28 L. Liu, Y. Yu, Y. Hou, J. Chai, H. Duan, W. Chu, H. Zhang, Q. Hu and J. Du, PLoS One, 2014, 9, e88348.

29 Y. Yu, X. Li, L. Liu, J. Chai, Z. Haijun, W. Chu, H. Yin, L. Ma, H. Duan and M. Xiao, Int. J. Biol. Sci., 2016, 12, 1213-1224.

30 E. Gouma, Y. Simos, I. Verginadis, E. Lykoudis, A. Evangelou and S. Karkabounas, Lab. Anim., 2012, 46, 40-45.

31 D. Cukjati, S. Rebersek and D. Miklavcic, Med. Biol. Eng. Comput., 2001, 39, 263-271.

32 C. M. Porth and K. J. Gaspard, Essentials of Pathophysiology: Concepts of Altered Health States: Third Edition, Wolters Kluwer Health/Lippincott Williams \& Wilkins, Philadelphia, 2011, pp. 64-65.

33 D. M. Lehmann, A. M. Seneviratne and A. V. Smrcka, Mol. Pharmacol., 2008, 73, 410-418. 
34 A. van der Vliet, Free Radical Biol. Med., 2008, 44, 938-955.

35 S. Yona, H. H. Lin, P. Dri, J. Q. Davies, R. P. Hayhoe, S. M. Lewis, S. E. Heinsbroek, K. A. Brown, M. Perretti, J. Hamann, D. F. Treacher, S. Gordon and M. Stacey, FASEB J., 2008, 22, 741-751.

36 K. Schopfer and S. D. Douglas, J. Lab. Clin. Med., 1976, 88, 450-461.

37 S. Schmaldienst and W. H. Horl, Nephrol., Dial., Transplant., 1996, 11, 1243-1245.

38 S. G. Adediran, D. J. Dauplaise, K. R. Kasten, J. Tschop, J. Dattilo, H. S. Goetzman, L. G. England, C. M. Cave, C. T. Robinson and C. C. Caldwell, Am. J. Physiol.: Regul., Integr. Comp. Physiol., 2010, 299, R918-R925.

39 M. Meisner, K. Tschaikowsky, T. Palmaers and J. Schmidt, Crit. Care, 1999, 3, 45-50.

40 I. C. Balc, H. Sungurtekin, E. Gurses, U. Sungurtekin and B. Kaptanoglu, Crit. Care, 2003, 7, 85-90.

41 D. M. Yealy and M. J. Fine, JAMA, J. Am. Med. Assoc., 2009, 302, 1115-1116.

42 E. A. Said, F. P. Dupuy, L. Trautmann, Y. Zhang, Y. Shi, M. ElFar, B. J. Hill, A. Noto, P. Ancuta, Y. Peretz, S. G. Fonseca, J. Van Grevenynghe, M. R. Boulassel, J. Bruneau, N. H. Shoukry, J. P. Routy, D. C. Douek, E. K. Haddad and R. P. Sekaly, Nat. Med., 2010, 16, 452-459.

43 M. B. Olszewski, A. J. Groot, J. Dastych and E. F. Knol, J. Immunol., 2007, 178, 5701-5709.

44 L. J. Walsh, G. Trinchieri, H. A. Waldorf, D. Whitaker and G. F. Murphy, Proc. Natl. Acad. Sci. U. S. A., 1991, 88, 42204224.

45 M. Maurer and E. von Stebut, Int. J. Biochem. Cell Biol., 2004, 36, 1882-1886.

46 M. Baggiolini, B. Dewald and B. Moser, Annu. Rev. Immunol., 1997, 15, 675-705.

47 E. Kindstedt, C. K. Holm, R. Sulniute, I. Martinez-Carrasco, R. Lundmark and P. Lundberg, Sci. Rep., 2017, 7, 5334.

48 R. Tabibiazar, R. A. Wagner, A. Deng, P. S. Tsao and T. Quertermous, Physiol. Genomics, 2006, 25, 194-202.

49 M. A. Grimbaldeston, S. Nakae, J. Kalesnikoff, M. Tsai and S. J. Galli, Nat. Immunol., 2007, 8, 1095-1104.

50 F. M. Brennan, P. Green, P. Amjadi, H. J. Robertshaw, M. Alvarez-Iglesias and M. Takata, Eur. J. Immunol., 2008, 38, 1106-1117.
51 M. R. Opp, E. M. Smith and T. K. Hughes Jr, J. Neuroimmunol., 1995, 60, 165-168.

52 M. Aste-Amezaga, X. Ma, A. Sartori and G. Trinchieri, J. Immunol., 1998, 160, 5936-5944.

53 T. K. Varma, T. E. Toliver-Kinsky, C. Y. Lin, A. P. Koutrouvelis, J. E. Nichols and E. R. Sherwood, Infect. Immun., 2001, 69, 5249-5263.

54 C. Nathan, Nat. Rev. Immunol., 2006, 6, 173-182.

55 M. B. Hampton, A. J. Kettle and C. C. Winterbourn, Blood, 1998, 92, 3007-3017.

56 A. K. Deodhar and R. E. Rana, J. Postgrad. Med., 1997, 43, 5256.

57 S. A. Leong, K. Cooper and F. J. W. M. Leong, Manual of diagnostic cytology, 2003, pp. 135-136.

58 H. Mudaliar, C. Pollock, M. G. Komala, S. Chadban, H. Wu and U. Panchapakesan, Am. J. Physiol. Renal Physiol., 2013, 305, F143-F154.

59 O. Boehm, P. Knuefermann, J. Plueck, M. Schwederski, H. Ehrentraut, S. Kebir, R. Lohner, M. Velten, S. Morath, A. Koch, K. Zacharowski, C. Grohe, A. Hoeft, G. Baumgarten and R. Meyer, J. Inflammation, 2013, 10, 33.

60 D. M. Rocha, A. P. Caldas, L. L. Oliveira, J. Bressan and H. H. Hermsdorff, Atherosclerosis, 2016, 244, 211-215.

61 C. A. Van der Graaf, M. G. Netea, S. A. Morre, M. Den Heijer, P. E. Verweij, J. W. Van der Meer and B. J. Kullberg, Eur. Cytokine Network, 2006, 17, 29-34.

62 X. Li, L. Liu, J. Yang, Y. Yu, J. Chai, L. Wang, L. Ma and H. Yin, EBioMedicine, 2016, 8, 72-82.

63 L. F. Chen and W. C. Greene, Nat. Rev. Mol. Cell Biol., 2004, 5, 392-401.

64 Q. Li and I. M. Verma, Nat. Rev. Immunol., 2002, 2, 725-734.

65 M. P. Rowan, L. C. Cancio, E. A. Elster, D. M. Burmeister, L. F. Rose, S. Natesan, R. K. Chan, R. J. Christy and K. K. Chung, Crit. Care, 2015, 19, 243.

66 B. Novakovic, M. Grujicic and L. Trajkovic-Pavlovic, Med. Pregl., 2009, 62(suppl. 3), 95-100.

67 G. Sikand, M. L. Kashyap and I. Yang, J. Am. Diet. Assoc., 1998, 98, 889-894; quiz 895-886.

68 D. C. D. E. Bloom and D. T. Jamsion, Finance Dev., 2004, 1015. 